\title{
Discussion on the Necessity and Realization of the Integrative Development of Tourism and Cultural In- dustry
}

Yang Dan

Hong Kong Polytechnic University

\begin{abstract}
With the development of socialist economy and the putting forward of "the Belt and Road" economic development strategy, all industries have developed vigorously, especially cultural industry and tourism. The integrative development of cultural industry and tourism can enhance the comprehensive competitiveness of regional economies, provide impetus for regional development, optimize industrial structure, and provide new ideas for the development of economies so as to promote economic growth. The integration and development of the two industries can not only achieve a mutually beneficial and win-win result, but also provide an example of the multi-industry coordinated development mode for the development of regional economy. This article first discusses the significance of the development of tourism and cultural industry, analyzes its significance for realizing the strategic target of regional economy. Then taking Sichuan province as an example, it elaborates the problems of system and creativity existing in the deep integration of tourism and cultural industry, and finally studies the way to realize it for reference.
\end{abstract}

Key words: cultural industry, tourism, integrative development, realization approach

Published Date: March 2018

Published Online: $31^{\text {st }}$ March 2018

\section{Introduction}

With the rapid development of high and new technology and the change of people's spiritual needs and consumption ideas, the technique fusion represented by digital convergence rapidly spread outside the information industry. The integration of industries has become a new trend of industrial development. New industry appears with the breaking of industrial boundaries and the integration of industries. At present, as an important feature of modern industrial development, industrial integration has become the focus of global economic development.

Since 2009, China has successively introduced five policies to promote the integrative development of cultural industry and tourism. According to the opinion of the State Council in 2004, efforts should be made to promote the integrative development of cultural creativity like architectural design service or advertising service and key industries like tourism or agriculture. Cultural industry and tourism are related to each other and integrate with each other in their respective development process, which broadens the market and enriches the product category. This can not only meet the needs of high-level consumers, but also gain more economic benefits. Therefore, the research on the integration of cultural industry and tourism is the demand of current development. It is also the theoretical need for studying the emergence of new industry from these two industries.

In addition, under the strategic background of "the Belt and Road", tourism, as a comprehensive modern service industry, can not only promote the exchanges among countries, but also improve the economic development of countries and regions along the line. Meantime, if the development of tourism can be integrated with cultural industry, foreign people's understanding of China's history and culture will be deepened unconsciously, so as to narrow the distance between hearts and achieve the purpose of "guiding, contacting, developing ". General Secretary Xi Jinping put forward the concept of "supply side reform" in the conference of the Central Leading Group for Financial and Economic Growth in October 2015. At the same time, Prime Minister Li Keqiang emphasized at the preparation meeting for the 13th Five-Year Plan that future economic development should focus on the supply side and the demand side, promote the development of industries toward the mid-to-high end. Therefore, promoting the integrative development of 
cultural industry and tourism as well as exploring the integration pattern and path has become the current key point to the cultivation of cultural tourism consumption hot spots and the promotion of cultural tourism connotation.

\section{Necessity of integration of cultural indus- try and tourism}

\subsection{Necessity of realizing the transformation and upgrading of the two industries}

At present, cultural industry and tourism in China have both entered the period of development transformation and important strategic upgrading. Deep excavation of cultural connotations and promotion of cultural taste are inevitable choices for tourism to accelerate the pace of transformation and upgrading, achieve differentiation, branding and sustainable development. Featuring high additional value, strong integration, and high brand influence, cultural industry provides new value-added points for tourism, which can accelerate the development of cross tourism, marginal tourism, and tourism that can meet the diverse needs of people. This greatly enriches the cultural connotation of tourism, promote the in-depth and diversified structural adjustment of tourism products, change the traditional resourceoriented development mode of "making a living in one's given circumstances". In turn, the transformation and upgrading of tourism provides innovative sources, market, financial support, and exchange platform for the rapid development of cultural industry, promoting its high-tech, high-quality and creative development.

\subsection{Integration greatly boost the economic growth}

The integrative development of cultural industry and tourism promotes and complements each other, produces a stronger butterfly effect, and achieves a win-win results for economic benefits. Compared with traditional industries, cultural tourism has the advantages of less environmental pollution and resource consumption, so it's an industry meeting the demands of sustainable development and the harmonious coexistence between human and nature. As an important part of modern service industry, cultural tourism industry, with its high additional value and high degree of association, is an important industry to stimulate economic growth, optimize industrial structure, and improve social and economic benefits. With large employment capacity and flexible forms of employment, cultural tourism industry is an effective channel to increase employment.

\subsection{Integration promote the sustainable devel- opment of culture industry and tourism}

With the progress of the society, culture has become a kind of productive force and an important form of capital. The integrative development of industries can not only enrich the connotation of tourism, but also let culture bring great economic benefits to tourism in the form of capital, add the value of tourism, and comprehensively enhance its competitiveness. The integrative development of cultural industry and tourism can promote the transformation and upgrading of industries. Both cultural industry and tourism are green energy industries, and the integration of these two industries can promote each other. The former provides creativity and cultural connotations for the latter, while the latter provides market for the former. The integrative development of them can extend the industrial chain of both industries, enrich their contents, diversify their types, promote their change of development patterns, and gradually let them realize the transformation and upgrading with the deep development of the integration.

\subsection{Integration accelerate the formation of tourism's brand effect}

Brand represents market, benefit, and competitiveness. With the increasing maturity of tourism consumption, consumers' consumption concept, pattern and structure are gradually changing. Their brand awareness has been enhanced, and their consumption desire has changed from low level to high level. Therefore, the formation of tourism brand can better meet the demands of tourism needs. In addition, different from other material products, tourism products cannot be transferred or stored, so it's difficult for consumers to know the performance and quality of the products in advance. The informedness of tourism products makes tourism brand very critical. Therefore, the formation of tourism's brand effect is not only the need of adapting to the development and change of tourism, but also the need of conforming to the trend of market economy.

\section{Problems existing in integrative devel- opment of cultural industry and tourism}

Sichuan province is taken as an example. Although, at present, the tourism and cultural industry in Sichuan has gained some experience and achievements in industrial integration, on the whole, its development is still in the primary stage, existing many problems, 
which are embodied in the following aspects.

\subsection{Unreasonable industrial structure}

The structure of cultural tourism resources development is unreasonable. It's necessary to deepen and enrich the connotation of existing resources, strengthen the protection of cultural tourism resources, give priority to "moderate exploitation, protection first", enhance the cultivation, promote the horizontal and vertical integration of cultural industry and tourism, achieve the sustainable development of cultural tourism industry.

At present, the cultural tourism in Sichuan province is in a state of "emphasizing the extension while overlooking the connotation", lacking in-depth experienceoriented products. Tourism and leisure products are in the majority, while representative products that have cultural connotations are insufficient. The unique cultural tourism resources in Sichuan Province has not been well used. The management of the cultural tourism products in the whole province is decentralized, and the scale is small. Good-quality cultural tourism products are in need. Therefore, the brand effect cannot be formed. In order to realize the overall optimization and upgrading of cultural tourism products, it's necessary to excavate deeply the cultural tourism resources in Sichuan Province, improve the cultural connotations of the products, integrate humanistic and natural tourism resources to the utmost extent. There is still only the display of culture heritage in most scenic spots, such as Thousand Buddha Rock and Huangze Temple in Guangyuan, Memorial Hall to Li Bai in Jiangyou, Jinsha Site Museum, Temple of Marquis and Du Fu's thatched cottage in Chengdu, as well as some temples that have religious and cultural characteristics in Mount Qingcheng and Mount Emei. Additional derivative products are few. The industrial structure needs further optimization.

\subsection{Imperfect management system}

The institutional problem is the obstacle that limits the integrative development of cultural industry and tourism. The cultural industry and tourism in Sichuan Province belong to two independent systems, and the head of each division does things in his own way without closely connecting with each other. Most of the cultural organizations and art groups in Sichuan Province are public institutions with imperfect market-connected system mechanism, poor operating capacity and low enthusiasm for the combination with tourism. Thus, they failed to open new ways for the development of tourism or inject new vitality into it. In addition, the administrative departments of cultural industry and tourism lack enough communication. Due to different responsibilities, cultural management department considers the development of cultural industry mostly from the perspective of cultural construction, lacking enough knowledge about how to introduce tourism, while tourism management department concentrates on tourism without having enough cultural resources to make full use of. Without much communication, these two departments make plans independently, so it is hard to form a unified planning and management of related resources.

\subsection{Weak market mechanism}

It is undeniable that government plays a dominant role in the development of the cultural tourism industry in Sichuan. Over the years, it has made a lot of efforts in providing administrative resources, strengthening market order, perfecting management standard, as well as cultivating market entities. However, just because the cultural tourism industry in Sichuan is dominated by government, its market mechanism is very weak, and the market entities grow quite slowly. Cultural tourism industry has an obvious promoting effect on economic growth. In order to make the cultural tourism industry in Sichuan vigorous, it must be given enough market space to let the market select the superior, so as to maintain the vitality of the market. However, at present, due to the weak market mechanism, the cultural tourism market in Sichuan does not have excellent external competitiveness, so it didn't get better development.

\subsection{Cultural tourism projects lacks creativity}

The lack of creativity is the main restriction of cultural tourism industry. Cultural tourism should be a cultural activity full of imagination and creativity. What we lack is the creativity that can change the cultural heritage into products which tourists are willing to see and experience, the creativity that can transform the cultural heritage into products, and the creativity that can well protect and develop tourism resources according to the Law on the Protection of Cultural Relics and the conservation regulations of tourist attractions. In order to integrate cultural industry with tourism, it's necessary to use innovative ideas to guide the development of cultural tourism industry, to excavate, integrate and activate "the soul of culture" existing in the tourism resources in Sichuan, instead of realizing the recognition and identification of the local humanity history through sticking to old ways or rebuilding the classic attractions. Sichuan, as one of the important witnesses of Chinese civilization, has made contributions to the 
profoundness and diversification of Central Plain culture, but it lacks the high-level creative projects that can directly show regional characteristics and reflect cultural tourism resources.

\section{Realization approaches to integrative de- velopment of cultural industry and tourism}

\subsection{Mode selection of integrative development of cultural industry and tourism}

This article divides the integration of cultural industry and tourism into three modes: factor integration, business function integration and market space integration. In the early stage, the integration of cultural industry and tourism features factor integration, and the degree of integration is not high. The mid-term stage features the integration of business and function of the two industries, and it has reached a certain scale. The degree of the integration in the later stage is high. At this time, the integration of market and space is the most important. The ultimate goal is to realize the integrative development of cultural industry and tourism.

\section{Fig. 1 Development Stages of Integrative Development of Cultural Industry and Tourism}

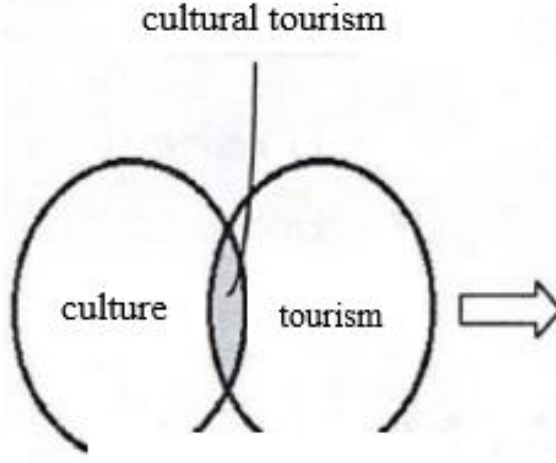

Factor integration

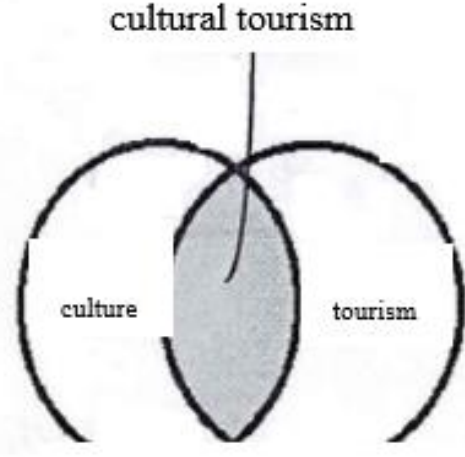

Business function integration

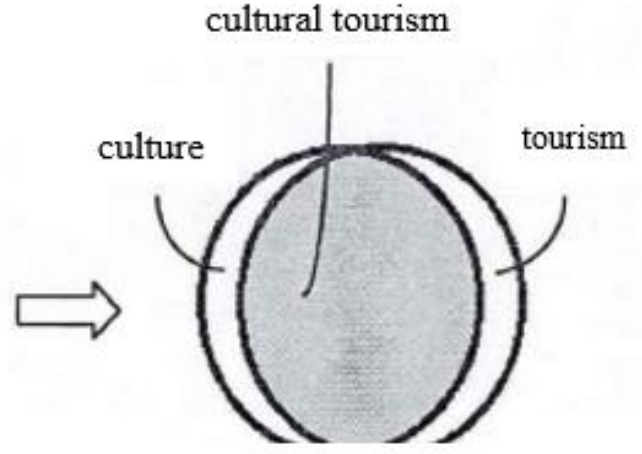

Market space integration
The integration of cultural industry and tourism can be divided into three stages. The first stage is the development and design stage in the early period of industrial integration. The second stage is the market management stage in the mid-term period of industrial integration. The third stage is the market consolidation stage in the later period of industrial integration. According to the characteristics and classifications of cultural industry and tourism, specifically, the integration of cultural industry and tourism will be embodied in the following aspects.

\subsubsection{Factor integration}

The integration of cultural industry and tourism is actually a step-by-step process from recessiveness to explicitness. In the early stage of industrial integration, every link of cultural industry and tourism has the opportunity of integration, which is in a recessive state. In order to break barriers and promote the integration, factor integration should be regarded as the basis. Then, only by making full use of space, market, function, technology, and the integration of products and resources can we optimize the industrial structure and improve its core competitiveness. Product is the basis of the development of any industries. Therefore, in the early stage of industrial integration, the first task is product design and development. This stage features factor integration, regards the integration of market resources as the basis of industrial integration, and develops products rich in selling points and core competitiveness through the combination of diversified integration.

We can create a series of cultural tourism products with advantages through the innovation of technology, combine the high-tech forms and creative ideas in cultural industry, and produce new-type tourism products with Sichuan characteristics to constantly attract consumers. At the same time, the catalysis of market will drive the emergence of a series of related enterprises to carry out a new round of market development. For example, now Sichuan province has one national base of animation and game, five flagship enterprises of animation and game industry, which can achieve the integrative development of animation industry and tourism, meet the demands of market through product upgrading and innovation, such as animation industry park, animation theme park, animation city or other cultural tourism products.

\subsubsection{Business function integration}

The initial stage, namely, product design has prepared the market. After that, the second stage is about how to extend the product chain and develop the market. The key point of this stage is to expand the influence and the market requirements of cultural tourism indus- 
try in Sichuan. Therefore, this article believes that the most important part of this stage is business function integration. It means to decide which products to continue to develop and which products to make corresponding adjustments based on the degree of adaptability to market of products in the first stage of industrial development. In the second stage of the integrative development of cultural industry and tourism in Sichuan, namely, the stage of product management, the integrative development can be achieved through the following modes. The six elements of tourism can be extended. They will penetrate and integrate with each other within the industry through the integration of market, and their functions can be achieved through technological innovation. For example, the essence of shopping tour is the integration of shopping and tourism. Turning shopping places into tourist attractions will not only promote tourism, but also stimulate the local economy. At the same time, tourist commodities industrial park is an effective mode of the integrative development within tourism system. It can promote the integration of cultural industry and tourism, form an industry and its core competitiveness.

\section{Fig. 2 Integration of Cultural Industry and Tourism}

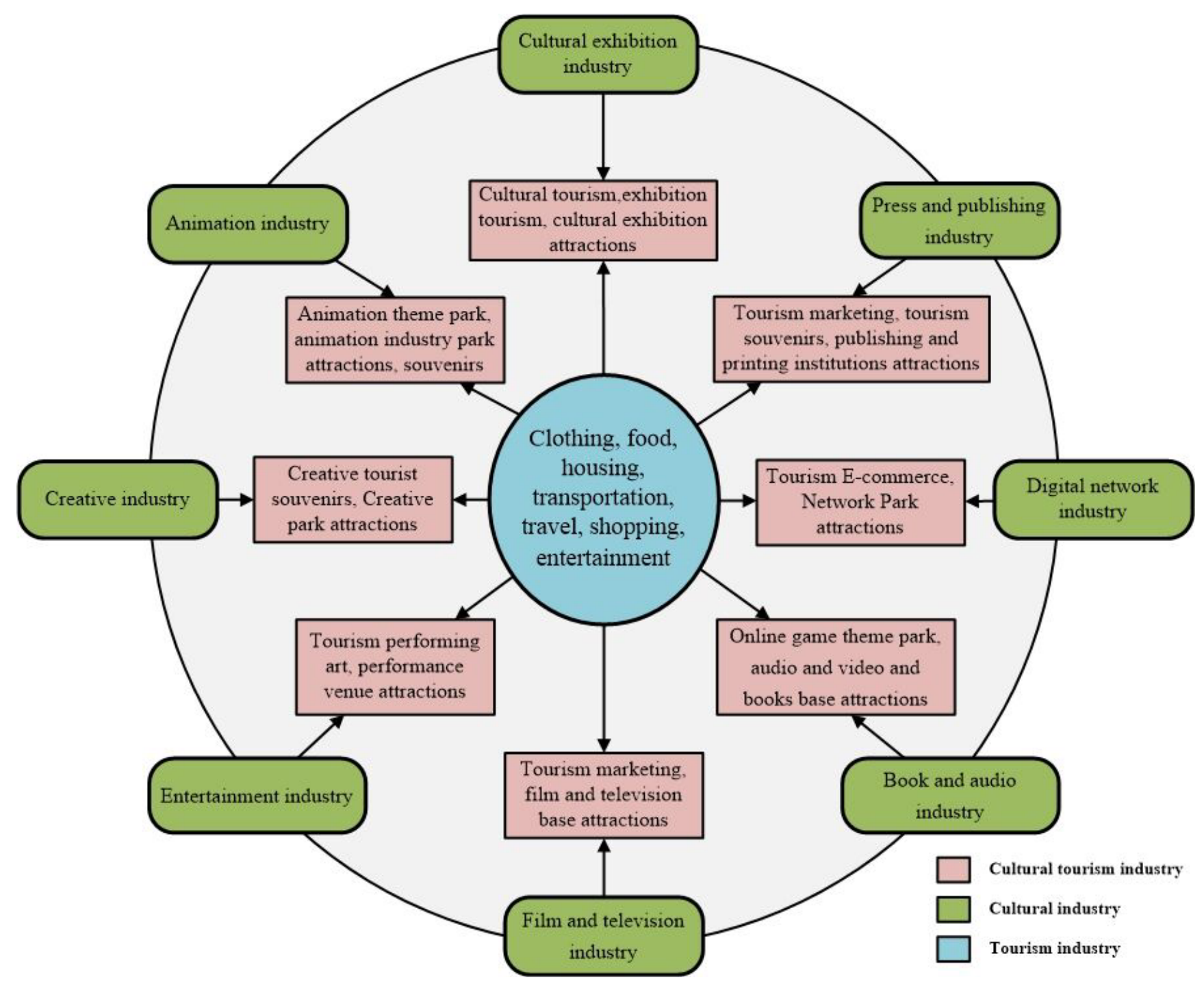

\subsubsection{Market space integration}

After the first two stages, namely, market development and expansion, the third stage is in the later period of industrial development. In this stage, we need to consolidate the original market, expand the influence of cultural tourism industry in Sichuan on the basis of maintaining the scale of the original market, and con- tinue to develop the potential market. Therefore, this stage features market space integration, focusing on the promotion of cultural tourism industry in Sichuan. The existing cultural tourism products in Sichuan will be integrated to form industrial clusters, and the integrative development of cultural industry and tourism will be achieved through the interinfiltration of indus- 
tries.

\subsection{Concrete measures for integrative develop- ment}

3.2.1 Focusing on innovation and cultural characteristics of Sichuan

Innovation is the dynamic source of the development of cultural industry. The support of innovation is needed in the process of transforming cultural resources into cultural capital, as well as developing cultural industry and products. The cultural industry in Sichuan must speed up the construction of innovation system, actively explore and innovate according to the characteristics and functions of the cultural resources in Sichuan and the needs of industrialization and marketization of resources, take cultural concept innovation as the guide, focus on the industry attributes of Sichuan culture and its functions of consumption and entertainment, emancipate from the limited cultural ideology and publicity, so as to achieve the industrialization development and marketization operation of the cultural resources in Sichuan. At the same time, we can produce products with more types by innovation to avoid the homogenization of products, promote the development of cultural tourism products through idea innovation, better integrate cultural industry with tourism, improve tourism innovation, and turn the cultural tourism resources in Sichuan into more wealth.

3.2.2 Strengthening introduction and training of professional talents

Human resource is the primary strategic resource in the era of globalization. The integrative development of cultural industry and tourism cannot be realized without human resources. Cultural or tourism products without creativity, design, resources integration or marketing are only primary resource-dependent products, with which the two industries cannot make any progress. Therefore, the introduction and training of talents related to cultural industry and tourism is of great importance. In the integration process of the culture industry and tourism in Sichuan, the cultural industry needs creative talents, technical talents, management and marketing talents, while the tourism industry mainly needs professional technicians, management talents, tour guides and service talents. In addition to the professional talents, with the promotion of modern science and technology, both the creation of cultural products and the development of tourism products need talents related to network and computer software. Moreover, a large number of reserve talents also need to be introduced. The on-the-job training for employees in tourism and cultural creative industry can not only enhance the professional skills of the practitioners, but also improve their cultural literacy, namely, cultural deposits, service consciousness, psychological quality, professional ethics, and service ability.

3.2.3 Making great efforts to build the brand of sichuan cultural tourism

Today, with great intangible value, brand is the most competitive resource. The brand image of the cultural tourism in Sichuan can be enhanced through the development of high-quality cultural tourism products with connotations, including related art activities, folk activities, and museum exchange exhibitions. Brand value consists of the brand awareness of consumers, high evaluation and loyalty. The popularity alone cannot form the brand. In addition to popularity, we should also pay attention to the quality of the development of Sichuan cultural tourism products and service, so that people can have a high regard for the cultural tourism products or services in Sichuan. Once good reputation brings higher additional value, the additional value of the brand will become more stable. Good reputation comes from the quality of the products, the cultural connotation of the brand, as well as technological innovation. Brand needs the perfect combination of popularity, good reputation and loyalty. Brand is an intangible asset, the build of which needs a long time. It cannot be accomplished in an action. Though intangible, brand is promoted by tangible assets. A competitive brand cannot be formed without good products. Therefore, we must make efforts in the quality, connotation and creativity of the cultural tourism in Sichuan, build the core scenic spots of the cultural tourism in Sichuan into brand name products with the promotion of the integrative development of cultural industry and tourism, so as to form a strong brand effect.

\subsection{Safeguard measures for integrative devel- opment of culture industry and tourism}

\subsubsection{Perfection and implementation of cultural sys- tem}

At present, due to the imperfect system of industrial integration, although China has introduced many policies conducive to the integration of cultural industry and tourism, the implementation degree and effect are not ideal. Firstly, cultural undertakings and cultural industries are not completely divided. Although many state-owned cultural enterprises have been reformed along with the reform of the cultural system, many problems still remain unresolved. For example, some art groups haven't changed their inherent ideology, still rely on the support of local government. They 
haven't realized the real marketization management. Therefore, we need to make and perfect relevant rules and laws, implement relevant policies and regulations, further deepen the reform of cultural system. Only when cultural industry truly realizes marketization operation can these two industries have a common development direction, so as to achieve the integrative development of industries. Deepening the reform of cultural system and changing the operation mode of enterprises are unavoidable issues in the fusion process of the culture industry and tourism in Baoji. Secondly, it is necessary to reasonably adjust the governmental regulation, break the traditional separated regulation, make adaptive adjustment, effectively plan the integrative development of cultural industry and tourism through strengthening target-oriented legislation and effectively relaxing the regulation, ensure the smooth development of the integration of tourism and cultural industry.

\subsubsection{Economic preferential policies}

According to the development needs of cultural tourism industry in different regions, for enterprises, preferential policies should be made in the aspects of land use, financial services, interest-free loan, investment and tax to help the development of enterprises. For talents, safeguard policies should be made in the aspects of housing allowance, medical insurance, salary and benefits, post allowances and to prevent the loss of talents and maintain the vitality of the main force of cultural tourism industry. In addition, in the aspect of the economic supervision of cultural tourism industry, in order to support the development of enterprises, credit aid can be provided for relevant enterprises after audit. Credit approval mechanism and loan management mechanism need to be formulated in line with the actual needs and characteristics of cultural tourism industry, so as to give appropriate convenience and preferential treatment to relevant enterprises and appropriately simplify the approval process. When encountering problems in the process of development, cultural tourism enterprises are allowed to mortgage intangible assets such as products, services, or intellectual property. Because the development of cultural tourism industry cannot be separated from the capital market, especially the financing subject and investment subject of the market, in order to develop healthily, cultural tourism industry needs to raise funds from the capital market. Therefore, it is very important to make efficient and safe investment and financing economic policies for the development of cultural tourism industry in Sichuan.

3.3.3 Perfecting legal protection of supervision system

Cultural tourism industry is an industry with strong comprehensiveness. It has wide involved aspects and numerous influencing factors, which leads to the occur- rence of "fragmented economy". However, at present, there is no specific legislation on cultural tourism in Sichuan. Therefore, the present task is to let the government refine the legal acts of cultural tourism industry and carry out strategic planning for it. In the aspect of legislation, the government plays a leading role in the formulation of government responsibilities, laws and regulations. As for the management system, governments in Sichuan province should guide and plan the development direction of cultural tourism, give full play to the supervision function on the change of management mechanism and market guidance, supervise and manage all aspects of the development of cultural tourism industry in Sichuan province, such as acts, price, construction, public order, planning and layout. In addition, in the process of legislation, government responsibilities must be clearly divided. The managing scope of provincial, municipal, and locallevel units should be explicit. All competent departments and industry associations perform their own functions to safeguard the market order of the cultural tourism industry in Sichuan.

\section{Conclusion}

In a word, to promote the integrative development of cultural industry and tourism is an inevitable choice for Sichuan province to achieve sustainable economic development. The comprehensive integration of culture industry and tourism is the foundation of the simultaneous innovation, promotion and transformation of the two industries. There are still many aspects that are worthy of promotion in the integrative development of Sichuan's cultural industry and tourism. Therefore, as for development ideas, we must take the scientific development view as the guidance, strengthen the comprehensive integration of cultural and tourism resources, products, and market, optimize and integrate resources, promote the integrative development of products, enhance the mutual benefit between cultural industry and tourism, make their respective advantages complementary to each other, adjust the structure, make scientific plans, insist on innovative development, make efforts to increase the productivity of cultural tourism industry, adapt to the increasing demands of cultural consumption, make cultural tourism industry become the new economic growth point and the pillar industry of Sichuan, so as to realize the strategic target of letting Sichuan become a province with strong tourism industry and cultural industry.

\section{References}

[1] Zhang Guangyu. The Integration of Tourism and Volume2; Issue 2 
Culture: the Route Selection of Jinan's Tourism Development[J]. Journal of the Party School of CPC Jinan Municipal Committee, 2010(4): 5-8.

[2] Hu Yongjia. An Economic Analysis of Industrial Integration[M]. Beijing: China Economic Publishing House, 2008.

[3] Guo Meibin. Thoughts and Countermeasures on the Cluster Development of Sichuan Cultural Tourism Industry[J]. Tourism Economy, 2012, (11).

[4] Qu Xiaoshuang, Li Xiaojuan. Research on the Inter- action Between Cultural Industry and Tourism in Henan Province[J]. Science and Technology Information, 2010(36): 378-379.

[5] Wen Shuman. Research on the International Competitiveness of China's Service Industry from the Perspective of Industrial Boundary[D]. Wuhan: Wuhan University of Technology, 2010.

[6] Zhou Jing. Research on the Integrative Development of Tourism and Cultural Industry in China[D]. Heilongjiang: Heilongjiang University, 2014. 